\title{
COMPOSITION OF MARKET PROCESSED CHEESE VARIETIES WITH PARTICULAR REFERENCE TO CHEESE
}

FAT.
Abd
El-Salam,
M.A. ${ }^{\text {; }}$
M.Naguib
M.M. El-Sayed.';

A. Abd El-Fattah';

Faiza M. Assem ${ }^{1}$ and

M. El-Aassar ${ }^{1}$

1- Dairy Department, National Research Center, Cairo, Egypt

2- Department of Dairy Science and Technology, Cairo University

\begin{abstract}
Forty five samples representing 15 brands of processed cheese (3 samples each) were grouped into two categories based on the origin of fat in cheese namely; cheeses containing exclusively milk fat and that containing vegetable fats. The cheeses were analysed for their fat, total solids and ash contents. Also, cheese fat was extracted and analysed for its diene contents and thiobarbeturic acid (TBA) values. Correlations between, diene contents and TBA values and reported values were calculated. The total solids and fat content of all samples were found to meet the requirements of the Egyptian Standards for processed cheese. Processed cheeses containing only milk fat had higher diene contents than that containing vegetable fats. Wide variations were observed in the TBA of cheese from different brands. Low correlations were found between diene and the conjugated linoleic content of cheese fat.
\end{abstract}

\section{INTRODUCTION}

Monitoring the composition of market processed cheese foods is important in order to assess changes in their quality and nutritive values over time.

The market of processed cheeses in Egypt is dynamic in terms of the number of varieties developed and changes in the quality and composition due to addition of vegetable oils practiced in several processed cheeses which would affect the properties of the product.

Previous studies (Mahfous et al, 1986; Khader et al, 1997; and ElSonbaty et al, 1997) on market processed cheeses had focused mainly on their general composition, rheological and microbiological quality and storage stability. However, very little has been done on the nurtritive values of processed cheeses.However, of the different functional constituents of processed cheese, conjugated linoleic acid (CLA) has received much attention in recent years. CLA has been reported to reduce the potential risk of some types of concer, its modulating effects on body weight and cardio vascular diseases (McDonald, 2000). Milk and ruminant fats are the natural rich sources of CLA, while vegetable oils are considered as a poor source of this constituent. (McDonald, 2000). Therefore, inclusion of vegetable oils would reduce the CLA content of processed cheeses. However, no cited study in the literature has delt with the CLA content of Egyptian processed cheeses.

The present paper describes the composition of market processed cheese varieties with particular reference to conjugated dienes as a simple measure of CLA content in these products. 


\section{MATERIALS AND METHODS}

Samples were randomly collected from 15 brands of market processed cheeses (3 samples each).

Time elapsed from the manufacturing date of these samples was not more than two weeks. The samples were devided into two groups according to information labled on the packages:

1- Samples containing vegetable oils (samples of 10 brands).

2- Samples containing milk fat only (samples of 5 brands).

The processed cheese samples were analysed for total solids by the direct oven method, and fat content by Gerber method as described by Ardo and polychronido (1999). Conjugated dienes were determined spectrophotometrically (AOAC, 1995) and thiobarbeturic acid as described by keeney, (1970). Data were statistically analysed as described by steel and Torrie (1980).

\section{RESULTS AND DISCUSSION}

Total solids (TS) and fat contents are only the essential requirement for the gross composition of processed cheeses in the Egyptian standards (ESO $2002 \mathrm{a}, \mathrm{b}$ ). therefore, market processed cheeses were analysed for these two parameters.

Table 1, shows that the TS of market processed cheese labled as containing vegetable oils ranged from 41.31 to $52.23 \%$ with an average of 46.58\%. Significant differences ( $\leq 0.01$ ) were found in TS between brands. All the cheeses were labled as full cream, however, the TS of only 7 brands met the legal requirement of full fat cheeses (ESO $2002 \mathrm{~b}$ ).

Table 1: Average composition, dienes contents and TBA of market processed cheese brands containing vegetable oils.

\begin{tabular}{|l|c|c|c|c|c|}
\hline Brand & Fat $\%$ & Fat/DM\% & T.S\% & TBA $^{*}$ & Dienes\% \\
\hline 1 & 23.67 & 46.65 & 50.46 & 0.055 & 0.073 \\
\hline 2 & 25.17 & 51.11 & 49.27 & 0.147 & 0.038 \\
\hline 3 & 23.00 & 46.88 & 49.08 & 0.07 & 0.066 \\
\hline 4 & 20.00 & 48.42 & 41.31 & 0.101 & 0.058 \\
\hline 5 & 26.83 & 59.34 & 45.22 & 0.15 & 0.046 \\
\hline 6 & 30.00 & 57.43 & 52.23 & 0.225 & 0.065 \\
\hline 7 & 25.00 & 57.91 & 43.17 & 0.11 & 0.075 \\
\hline 8 & 24.83 & 57.44 & 45.59 & 0.075 & 0.058 \\
\hline 9 & 24.83 & 55.15 & 45.03 & 0.112 & 0.321 \\
\hline 10 & 26.83 & 60.43 & 44.4 & 0.117 & 0.030 \\
\hline Total average & $\mathbf{2 5 . 0 2}$ & $\mathbf{5 3 . 7 8}$ & $\mathbf{4 6 . 5 8}$ & $\mathbf{0 . 1 1 6}$ & $\mathbf{0 . 0 8 3}$ \\
\hline
\end{tabular}

* Absorbance at $538 \mathrm{n} \mathrm{m}$.

These results are in agreement with that reported by Mahfouz et al (1986), El-Sonbaty et al (1997) and Khader et al (1997). The changes in the TS of processed cheeses can be attributed to differences in batches and/or differences in time elapsed between cheese mamufacture and analysis, which allow for slight decrease in cheese moisture (Khader et al, 1997). 
The fat content of processed cheeses containing vegetable oil ranged from 44.8 to $60.94 \%$ on dry basis (Table 1 ). This indicates that all analysed samples met the minimum requirement for fat content in the Egyptian standards for full fat product (ESO, 2002 b) namely $45 \%$. Similar results were reported by Mahfouz et al (1986), El-Sonbaty et al (1997) and Khader et al (1997).

The TS of cheeses containing milk fat only (5 brands) ranged from 33.14 to a maximum of $46.18 \%$ with an average of $42.32 \%$ (Table 2). The brand with minimum TS content was labled as light (Low fat), however, the other 4 being labled as full - fat. Only, the average TS of one brand satisfied the legal requirement for TS in full fat processed cheese (ESO, $2002 \mathrm{a}$ ).

Differences in the TS of cheese from different brands were found significant $(P \leq 0.01)$ (Table 4).

Table (2): Average composition, dienes contents and TBA of market processed cheese brands containing milk fat only.

\begin{tabular}{|l|c|c|c|c|c|}
\hline Brand & Fat\% & Fat/DM\% & T.S\% & TBA $^{*}$ & Dienes\% \\
\hline 11 & 26.67 & 60.18 & 44.31 & 0.181 & 0.239 \\
\hline 12 & 25.00 & 55.20 & 45.26 & 0.136 & 0.087 \\
\hline 13 & 10.50 & 31.66 & 33.19 & 0.3 & 0.055 \\
\hline 14 & 25.33 & 56.56 & 44.79 & 0.11 & 0.103 \\
\hline 15 & 24.17 & 54.87 & 44.04 & 0.105 & 0.175 \\
\hline Total average & $\mathbf{2 2 . 3 3}$ & $\mathbf{5 1 . 6 9}$ & $\mathbf{4 2 . 3 2}$ & $\mathbf{0 . 1 6 6}$ & $\mathbf{0 . 1 3 2}$ \\
\hline
\end{tabular}

* Absorbance at $538 \mathrm{n} \mathrm{m}$.

In 4 brands, the fat content ranged from a minimum of 52.03 to a maximum $60.84 \%$ on dry matter basis (Table 2). One brand (No. 3) being labled as light which contained on average fat content of $31.66 \%$ in Dry matter which can be classified as half - fat processed cheese (ESO, 2002 a). However, this brand did not satisfy the legal requirement for falf processed cheese with respect to the total solids content. Based on the present result and previous ones, it is suggested that the Egyptian standards for processed cheeses should be modified for:

1- The processed cheeses should be labled according to the classification given in the standard.

2- That an upper limit for fat content should be given for each class in addition to the minimum limit in the standard.

The TBA is a measure of fat oxidation. TBA in the Processed cheeses containing vegetable oils showed wide variations between brands and within the replicates of the some brand (Table 1). Differences in TBA between brands were significant $(P \leq 0.05)$ (Table 3$)$. The high TBA of cheese fat suggests that the vegetable oils used in cheese manufacture had high TBA valves and/or that cheese fat was subjected to fat oxidation during storage.

The TBA of Processed cheese containing milk fat only in these brands ranged from 0.056 to 0.436 with an average of 0.166 (Table 2). However, differences in TBA of cheese fat were found not significant. Comparing the TBA of processed cheese containing vegetable oils (Table 1) with that of processed cheese containing milk fat only (Table 2), indicated that the former had less average TBA value than the latter. This can be 
explained on the basis of the high natural antioxidants in vegetable oils (Hui, 1995) Also, less matured cheese is usually used in the manufacture of cheese containing vegetable oils as compared with that containing milk fat only. Matured cheese would develop noticeable fat oxidation during maturation.

Table (3): Analysis of variance of differences in composition, dienes contents and TBA between market processed cheese brands containing vegetable oils:

\begin{tabular}{|l|c|c|}
\hline Constituent & F calculated & Significance \\
\hline Fat & 24.8 & $\mathrm{P} \leq 0.01$ \\
\hline Fat / DM & 13.24 & $\mathrm{P} \leq 0.01$ \\
\hline TS & 41.67 & $\mathrm{P} \leq 0.01$ \\
\hline TBA & 3.049 & $\mathrm{P} \leq 0.05$ \\
\hline Dienes & 1.418 & Not significance \\
\hline
\end{tabular}

Tabulated $\mathrm{F} \leq 0.05=2.46, \leq 0.01=3.60$

Table (4): Analysis of variance of differences in composition, dienes contents and TBA between market processed cheese brands containing milk fat only:

\begin{tabular}{|l|c|c|}
\hline Constituent & F calculated & Significance \\
\hline Fat & 115.416 & $\mathrm{P} \leq 0.01$ \\
\hline Fat / DM & 71.82 & $\mathrm{P} \leq 0.01$ \\
\hline TS & 144.52 & $\mathrm{P} \leq 0.01$ \\
\hline TBA & 3.774 & Not significance \\
\hline Dienes & 3.222 & Not significance \\
\hline
\end{tabular}

Tabulated $\mathrm{F} \leq 0.05=3.84, \leq 0.01=7.01$

Dienes is a generic name for fatty acid contining 2- conjugated double bonds irrespective their position on the number of carbon atoms in the fatty acids. Table 1 shows that the diene content of processed cheese containing vegetable oils ranged rom 000 to $0.138 \%$ with an average of $0.082 \%$. Differences in the dienes content of processed cheese from these brands were found not significant (Table 3). Generally, processed cheese containing vegetable oils had less dienes than processed cheese with milk fat only (Table 3 ).

Milk fat was reported to contain high conjugated dienes content than vegetable oils (McDonald, 2000).

The dienes content of processed cheeses containing milk fat only (Table 2) ranged from 000 to $0.428 \%$ with an average of $0.131 \%$ respectively. Differences in the dienes content of these brands were found not significant.

Interrelationships between constituents of market processed cheeses were indicated in table 5,which shows the correlation coefficient, slope and intercept for regression analysis of fat, TS, TBA, and dienes of market processed cheese containing vegetable oil. The same for processed cheese containing milk fat only is shown in table 6 .

In case of processed cheese containing vegetable oil that relation between fat and TS content and between fat and TBA were found significant $(P \leq 0.01)$ with correlation coefficient of 0.417 , respectively. Other relations, 
namely fat and dienes, TBA and dienes, TS and dienes, TS and TBA were found not significant. This suggests that determination of dienes is not an accurate measure of CLA in the cheese samples.

The relation of fat and TS, fat and TBA and TS and TBA of processed cheese containing milk fat only were found insignificant. These agree with the relation between constituent of processed cheese with vegetable oil.

Table (5): Interrelationships between composition, dienes contents and TBA values of processed cheese brands containing vegetable oils:

\begin{tabular}{|l|c|c|c|c|c|}
\hline \multicolumn{1}{|c|}{} & $\mathbf{R}$ & $\mathbf{r}^{2}$ & Slope & Intercept & Significance \\
\hline Fat \& T.S & 0.47 & 0.221 & 0.615 & 31.18 & S \\
\hline Fat \& TBA & 0.416 & 0.173 & 0.013 & -0.203 & S \\
\hline Fat \& Dienes & -0.088 & 0.008 & -0.003 & 0.1635 & N.S \\
\hline TBA \& Dienes & -0.044 & 0.002 & -0.053 & 0.088 & N.S \\
\hline T.S \& Dienes & -0.061 & 0.004 & -0.002 & 0.162 & N.S \\
\hline T.S \& TBA & 0.149 & 0.022 & 0.003 & -0.047 & N.S \\
\hline
\end{tabular}

Table (6): Interrelationships between composition, dienes contents and TBA values of processed cheese brands containing milk fal only.

\begin{tabular}{|l|c|c|c|c|c|}
\hline \multicolumn{1}{|c|}{} & $\mathbf{R}$ & $\mathbf{r}^{\mathbf{2}}$ & Slope & Intercept & Significance \\
\hline Fat \& T.S & 0.979 & 0.959 & 0.749 & 25.59 & S \\
\hline Fat \& TBA & -0.607 & 0.368 & -0.011 & 0.401 & S \\
\hline Fat \& Dienes & 0.372 & 0.139 & 0.007 & -0.019 & N.S \\
\hline TBA \& Dienes & 0.197 & 0.039 & 0.205 & 0.097 & N.S \\
\hline T.S \& Dienes & 0.37 & 0.137 & 0.009 & -0.237 & N.S \\
\hline T.S \& TBA & -0.608 & 0.37 & -0.014 & 0.749 & S \\
\hline
\end{tabular}

\section{REFERENCES}

AOAC, (1995). Association of Official Analytical Chemists in Official Methods. Chapter $41,16^{\text {th }}$ edn. Association for Official Analytical Chemists Washington D.C. pp 13-16.

Ardo and Polychorido, (1999). Laboratory Manual for Chemical Analysis of cheese. European Commission.

El - Sonbaty, A.H., Badawi, R.M. and kebary, K.M.K. (1998) Nutritional quality of Egyptian processed cheese. Egyptian J. Dairy Sci., 26: 139150.

Hui, Y.H. (Ed.), (1995). Bailey's Industrial oils and fat products, Edible oil and fat products: products and Application technology $5^{\text {th }} \mathrm{Ed}$ wileyinter science pp 600.

Khader, A., Hamed, A., AL-Khamy, A.F., EL-Garawany, G.A. and Abd -ELSalam, M.H. (1997). Chemical composition and some properties of market processed cheese. Egyptian J. Dairy sci., 25: 269-279.

Mahfouz, M.B., EL-Dein, H.F., EL-Shibiny, S., Haggag, H.F. and Magdoub, M.N. (1986). Chemical and microbiological quality of market processed cheese. Egyptian J. Dairy Sci., 14 : 33-41. 


\section{Abd El-Salam M.H. et al.}

Mac Donald, H.B. (2000). Conjugated Linoleic acid and cheese prevention; A review of current knowledge. J. Am. College. Nutr., $19: 1115-1185$.

Steel, R.G.D. and Torrie, J.H. (1980). Principle and procedures of statisticals. A biometrical approach $2^{\text {nd }}$ Ed. Mc Graw - Hill Book. Co. New York.

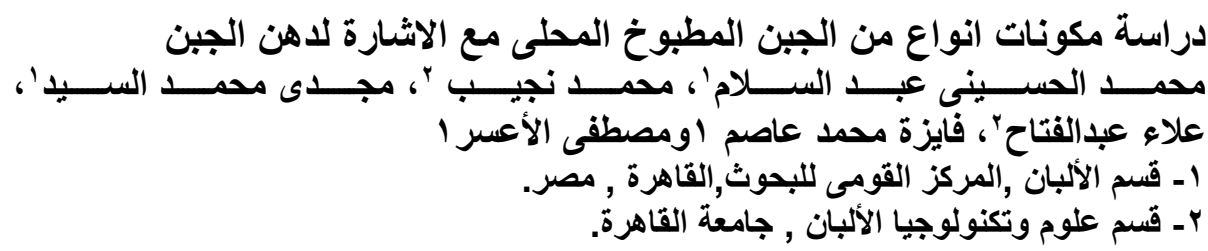

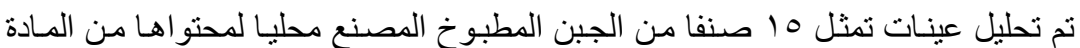

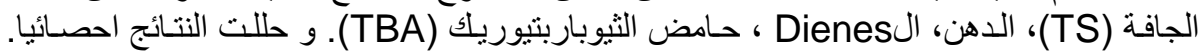

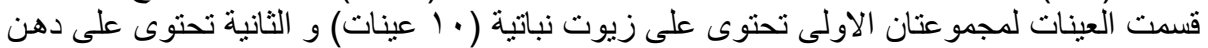

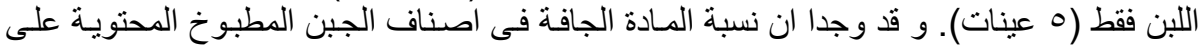

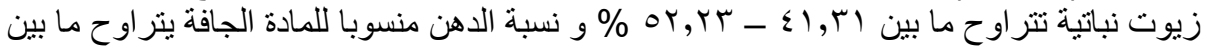

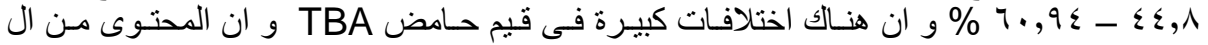

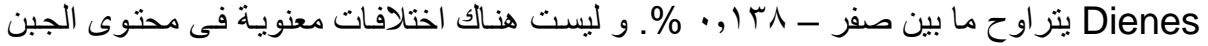

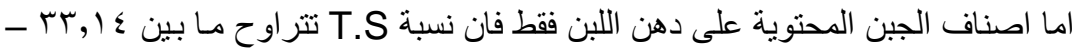

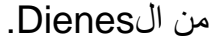

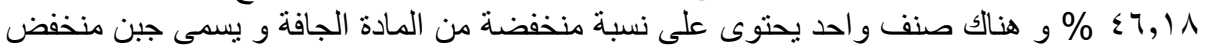

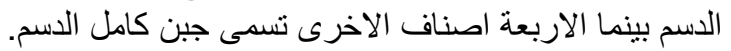

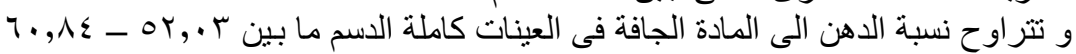

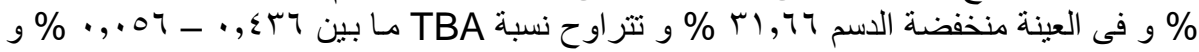

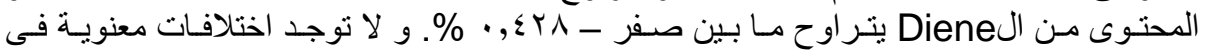

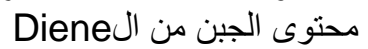

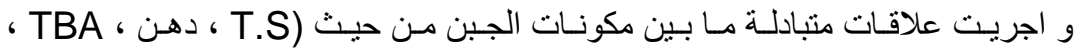

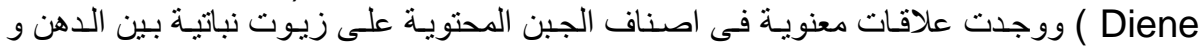

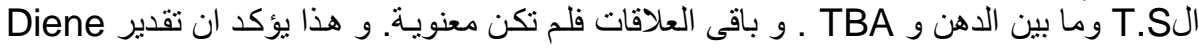

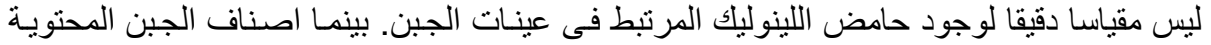

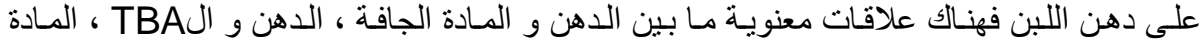
الجافة و الTBA و هذا يتفق مع العلاقة ما بين مكونات الجبن المطبو خ المحتوى على زيون الليوت نباتية. 